\title{
Evolution of Catkins: Inflorescence Morphology of Selected Salicaceae in an Evolutionary and Developmental Context
}

\author{
Quentin C. B. Cronk ${ }^{1 *}$, Isabelle Needham ${ }^{2}$ and Paula J. Rudall ${ }^{2}$ \\ ${ }^{1}$ Department of Botany, University of British Columbia, Vancouver, BC, Canada, ${ }^{2}$ Royal Botanic Gardens, Kew, London, UK
}

Poplars (Populus sp.) and willows (Salix sp.) are well known woody plants common throughout the northern hemisphere, both with fully sequenced genomes. They bear compact unisexual inflorescences known as "catkins." Closely related genera of the "salicoid clade" within the family Salicaceae include the Asian genera Bennettiodendron, Idesia, Itoa, Poliothyrsis, and Carrierea and the Central American genera Olmediella and Macrohasseltia. Like willow and poplar, most of these genera are dioecious, but unlike

OPEN ACCESS

Edited by:

Verónica S. Di Stilio,

University of Washington, USA

Reviewed by:

Jill Christine Preston,

University of Vermont, USA

Madelaine Elisabeth Bartlett,

University of Massachusetts Amherst,

USA

*Correspondence: Quentin C. B. Cronk

quentin.cronk@ubc.ca

Specialty section:

This article was submitted to Plant Evolution and Development,

a section of the journal

Frontiers in Plant Science

Received: 27 August 2015 Accepted: 06 November 2015 Published: 07 December 2015

Citation:

Cronk QCB, Needham and Rudall PJ (2015) Evolution of Catkins: Inflorescence Morphology of Selected Salicaceae in an Evolutionary and Developmental

Context. Front. Plant Sci. 6:1030. doi: 10.3389/fp/s.2015.01030 willow and poplar they generally have loosely branched panicles rather than catkins, and less highly reduced flowers. However, the early developing inflorescences of Carrierea and Idesia show similarities to catkins which suggest possible pathways by which the salicoid catkin may have evolved.

Keywords: inflorescence evolution, heterochrony, synorganization, preformation, dioecy, floral reduction, inflorescence architecture, genome-enabled model system

\section{INTRODUCTION}

\section{The Catkin and its Recurrent Evolution}

The catkin is a type of compact or string-like inflorescence characterized by a single relatively stout axis on which unisexual sessile or subsessile apetalous flowers are clustered in a spiral or whorled arrangement. It is an extremely striking characteristic of many common trees, particularly of northern temperate regions. Notable among these are members of the order Fagales (oaks, walnuts, hazels, birches, and alders) and the relatively distantly related family Salicaceae s. str. (willows and poplars). The similarities between the catkins of these two groups led to them being classified together for a century (see below). It is now accepted that the presence of catkins in the two groups is the result of convergent evolution.

In this paper 'catkin' will be used in preference to the alternative term 'ament.' According to the Oxford English Dictionary, the word catkin came into English in 1578 when Henry Lyte (1529-1607) coined it in his translation of Dodoens' New Herbal as a translation of the Dutch "katteken" (kitten) used for the downy inflorescences of willows and other plants (Dodoens, 1578). The botanical Latin equivalent, amentum, the Latin word for a thong or string, is less common. Its use in English dates from the late 18th century, sometimes anglicized as ament. The use of amentum in botanical Latin overlooks the Latin word for catkin, iulus, used as such by Pliny. However, apart from the occasional use of Juliflorae instead of Amentiflorae, this form never became established. 


\section{The Catkin and Taxonomy}

The striking amentaceous inflorescences of many trees quickly attracted the attention of botanists, some of whom thought that the catkin-bearing trees formed a natural group (variously called Amentiflorae, Amentiferae, Amentales, or Amentaceae; Stern, 1973). Although the group name "Amentacea" was used by Gmelin, Linnaeus, and de Jussieu (Stern, 1973) and sporadically by later authors (Du Mortier, 1825), it was Eichler who was most influential in defining a 'scientific' Amentaceae. In the third edition of Eichler's Syllabus (Eichler, 1883) the order Amentaceae comprised the Cupuliferae (i.e., Betulaceae and Fagaceae s.l.), Juglandaceae, Myricaceae, Salicaceae, and Casuarinaceae. This collection of families can be considered the canonical Amentiferae, although other groups have drifted in and out of the catkin-bearing alliance in various systems, e.g., Piperaceae, Urticales, Leitneria, Garryales (Figure 1). Remarkably, Eichler's (1883) Amentaceae is a good natural group (providing of course that the unrelated Salicaceae is excised). In fact it corresponds almost exactly to the modern concept of the Fagales (Angiosperm Phylogeny Group, 2009), missing only Rhoiptelea and Ticodendron, both unknown to Eichler.

In the last century the realization grew that the Salicalean branch of the Amentiferae was very different from the Fagalean

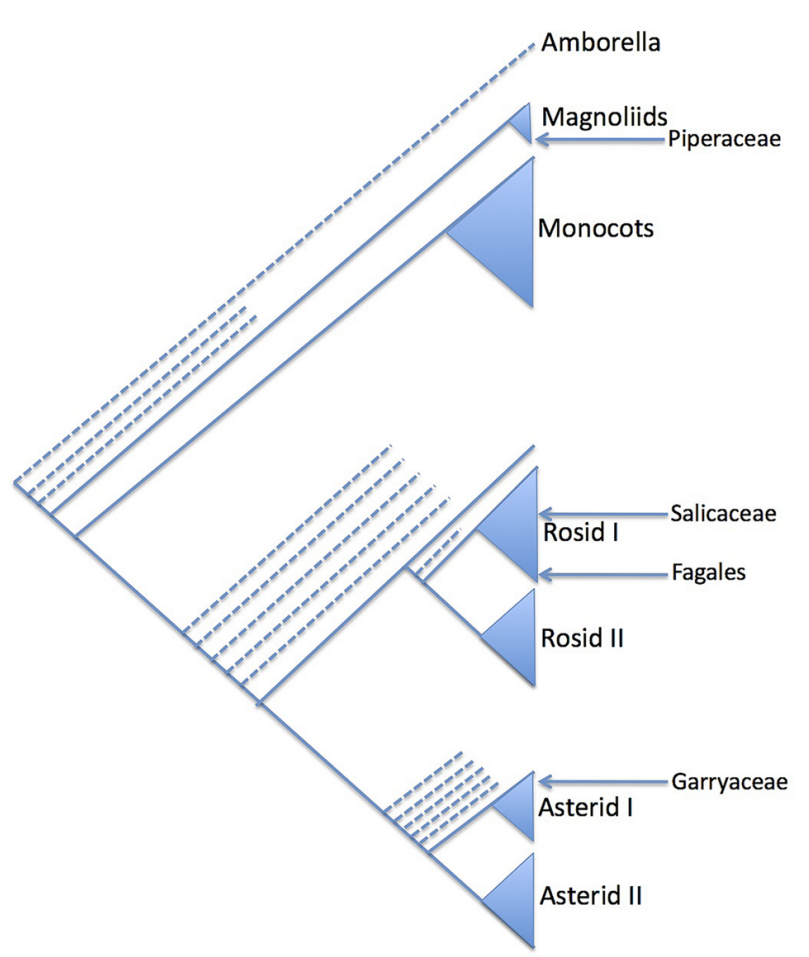

FIGURE 1 | Summary phylogenetic diagram showing the relative phylogenetic position (arrowed) of selected groups that have formerly been included in the Amentiferae due to their catkins or catkin-like inflorescences (see text). The phylogeny reflects that of the Angiosperm Phylogeny Group (2009). Only major clades are shown: the position of minor clades is indicated with dashed lines.
Amentiferae (Figure 1). This realization was confirmed by molecular phylogenetics and made clear in systems based on molecular phylogenetics such as the Angiosperm Phylogeny Group (APG) system (Angiosperm Phylogeny Group, 2009). An implication of the decomposition of the Amentiferae is that catkins, the most obvious unifying feature of the Amentiferae, have evolved in two very distinct lineages. This raises questions of convergent evolution: how the catkin evolved in each case and what the ancestral inflorescence form might be. Here we use comparative ontogenetic and anatomical observations as a basis to discuss these questions in one of the archetypal catkin-bearing groups, Salicaceae.

\section{The Salicaceae, Classification and Morphology}

When Eichler included Salicaceae within his order Amentaceae, the family was wholly amentiferous (i.e., catkin-bearing) comprising only the genera Salix and Populus. Molecular evidence, coupled with support from phytochemistry and morphology, has demonstrated a close relationship between Salix and Populus and many non-amentiferous genera that were formerly placed in the Flacourtiaceae (Leskinen and Alstrom-Rapaport, 1999; Chase et al., 2002; Alford, 2005). The heterogeneous family Flacourtiaceae is now dismembered, and its members are placed in other families, mainly the Salicaceae and Achariaceae. The family Salicaceae, as now circumscribed in the broad sense, is a more homogeneous group of about 1000 species in c. 55 genera. They are uniformly woody (trees or shrubs) with simple, usually alternate, leaves. The leaves are often dentate and the leaf teeth frequently glandular (characteristic 'salicoid teeth'). The flowers are often inconspicuous and a perianth may be lacking in some genera. Inflorescence morphology in the family as a whole is highly variable. The sister family to the Salicaceae is probably the Lacistemataceae (Davis et al., 2005; Korotkova et al., 2009), and it is of interest that this family has also independently evolved catkins.

Salix and Populus are closely related sister genera which in turn are related to a group of seven other genera (Alford, 2005). Initial molecular phylogenetic evidence based on ITS and eight plastid regions suggests that "a clade consisting of Bennettiodendron, Idesia, and Olmediella are sister to Salix and Populus (Figure 2). Sister to that clade is a clade of the other four genera, Carrierea, Itoa, Macrohasseltia, and Poliothyrsis" (Alford et al., 2009).

These nine genera have been referred to as the "salicoid clade" of the family Salicaceae (Cronk, 2005). Salix and Populus are known to be palaeotetraploid (Sterck et al., 2005) with a primary chromosome number of $n=19$ (Darlington and Wylie, 1955) whereas the haploid base number for the family is $n=9$ or 11 . For instance, Azara serrata Hook is $n=9$ (Sanders et al., 1983). Very few chromosome counts exist for the genera of the salicoid clade but both Olmediella (Grill, 1990) and Idesia (Darlington and Wylie, 1955; Grill, 1990) appear to be tetraploid at $n=22$. It is possible therefore that whole of the salicoid clade shares the same palaeotetraploidy event from $n=11$ to $n=22$, followed by (in Populus and Salix) reduction events to $n=19$. 


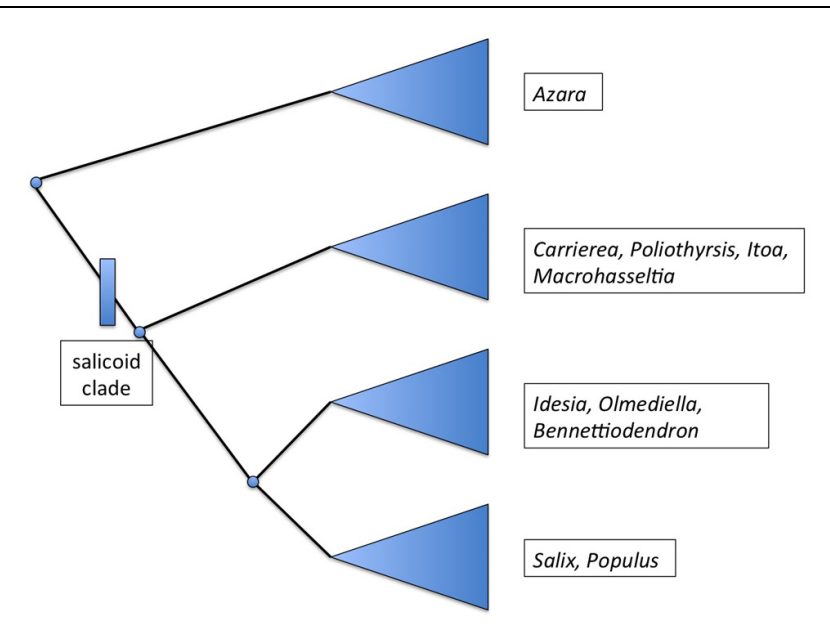

FIGURE 2 | Summary phylogenetic diagram showing the major groupings within the salicoid clade, after Alford et al. (2009).

\section{The Inflorescence of the Salicoid Clade of the Salicaceae}

The genera of the salicoid clade have been described in various recent treatments (Sleumer, 1980; Fang et al., 1999; Yang and Zmartzty, 2007). They are all described as having paniculate inflorescences with the exception of Populus and Salix which have racemose inflorescences (catkins). A reduction of inflorescence branching (from panicle to raceme) does occur as a sexual dimorphism in Itoa, in which the male flowers are said to be in racemes and the female flowers in panicles (Table 1). Furthermore, in Idesia the paniculate inflorescences are long, pendulous and fairly narrow, superficially resembling racemes (Figure 3).
In the fossil record there is some blurring between raceme and panicle. Pseudosalix ${ }^{\dagger}$ (Boucher et al., 2003) is an Eocene fossil of Salicaceae that has leaves like willow (Salix) but somewhat paniculate inflorescences. Furthermore, the Eocene Populus tidwellii ${ }^{\dagger}$ Manchester, Judd \& Handley (Boucher et al., 2003; Manchester et al., 2006) has catkins with some lateral branching near the base, placing it in an intermediate position in this character with the paniculate ancestors of Populus. Furthermore, Fisher (Fisher, 1928a,b) argued that the bract (with which the flower is associated), while appearing to be directly inserted on the main axis of the inflorescence, is in fact inserted on a minute lateral stump (which Fisher called the "internode") at the top of which the flower is borne. She argued that this feature is an indication of the evolution of the Salicaceae catkin from a branched, paniculate antecedent.

In most of the salicoid clade, the inflorescence is terminal on the shoots, often (as in Idesia, Carrierea, and Poliothyrsis) terminating the shoots that appear after bud-break of the terminal bud. This condition contrasts with Salix and Populus, in which the inflorescences are produced in lateral buds (with very few exceptions: in Salix sect. Chamaetia they are often terminal). Again, P. tidwellii ${ }^{\dagger}$ (Manchester et al., 2006) is interesting in this regard as it has terminal inflorescences.

\section{Floral Morphology of the Salicoid Clade}

Apart from unisexuality, lack of petals and the presence of nectarial disk glands in some species, the flowers of the most genera in the salicoid clade are unexceptional.

The flowers all have a subtending bract. The highly reduced flowers in Salix and Populus prompted some early authors to suggest that the bracts in thes taxa might be derived from the missing perianth. However, this interpretation was shown to be false by Fisher (1928a,b) who demonstrated that they have a foliar-type vascularization consistent with bract origin: these

TABLE 1 | Genera of the salicoid clade of Salicaceae.

\begin{tabular}{|c|c|c|c|c|c|}
\hline Genus & No. of sp. & $\begin{array}{l}\text { Sex of } \\
\text { flowers }\end{array}$ & $\begin{array}{l}\text { Distribution of } \\
\text { sexes }\end{array}$ & Inflorescence & Perianth and disk \\
\hline Bennettio-dendron & 3 (Asia) & Unisexual & Dioecious & Terminal or axillary panicles & $\begin{array}{l}\text { Sepals } 3 \text {, petals } 0 \text {, disk glands } \\
\text { numerous, small }\end{array}$ \\
\hline Carrierea & 2 (Asia) & Unisexual & Dioecious & $\begin{array}{l}\text { Short terminal or axillary } \\
\text { panicles }\end{array}$ & Sepals 5 , petals 0 , disk glands 0 \\
\hline Idesia & 1 (Asia) & Unisexual & Dioecious & $\begin{array}{l}\text { Long raceme-like terminal or } \\
\text { axillary panicles }\end{array}$ & $\begin{array}{l}\text { Sepals c. } 5 \text {, petals } 0 \text {, disk glands } \\
\text { numerous among stamens or } \\
\text { staminodes }\end{array}$ \\
\hline Itoa & 1 (Asia) & Unisexual & $\begin{array}{l}\text { Dioecious (or partly } \\
\text { monoecious?) }\end{array}$ & $\begin{array}{l}\text { Terminal panicles (f) or terminal } \\
\text { or axillary racemes }(\mathrm{m})\end{array}$ & Sepals 5 , petals 0 , disk glands 0 \\
\hline Macrohasseltia & 1 (S. Am.) & & & & \\
\hline Olmediella & 1 (C. Am.) & Unisexual & Dioecious & Small panicles & $\begin{array}{l}\text { Sepals } 5 \text { (reduced), petals 0, disk } \\
\text { glands numerous (at base of each } \\
\text { stamen) }\end{array}$ \\
\hline Poliothyrsis & 1 (Asia) & Unisexual & Monoecious & $\begin{array}{l}\text { Terminal panicle, upper flowers } \\
\text { female }\end{array}$ & Sepals 5 , petals 0 , disk glands 0 \\
\hline Populus & c. 60 (wide) & Unisexual & Dioecious & Catkin & Sepals 0, petals 0, disk cupular \\
\hline $\begin{array}{l}\text { Salix (incl. Chosenia which has } \\
\text { both disk glands absent) }\end{array}$ & c. 500 (wide) & Unisexual & Dioecious & Catkin & $\begin{array}{l}\text { Sepals } 0 \text {, petals } 0 \text {, disk glands us. } \\
2 \text { (adaxial and abaxial; abaxial may } \\
\text { be absent) }\end{array}$ \\
\hline
\end{tabular}



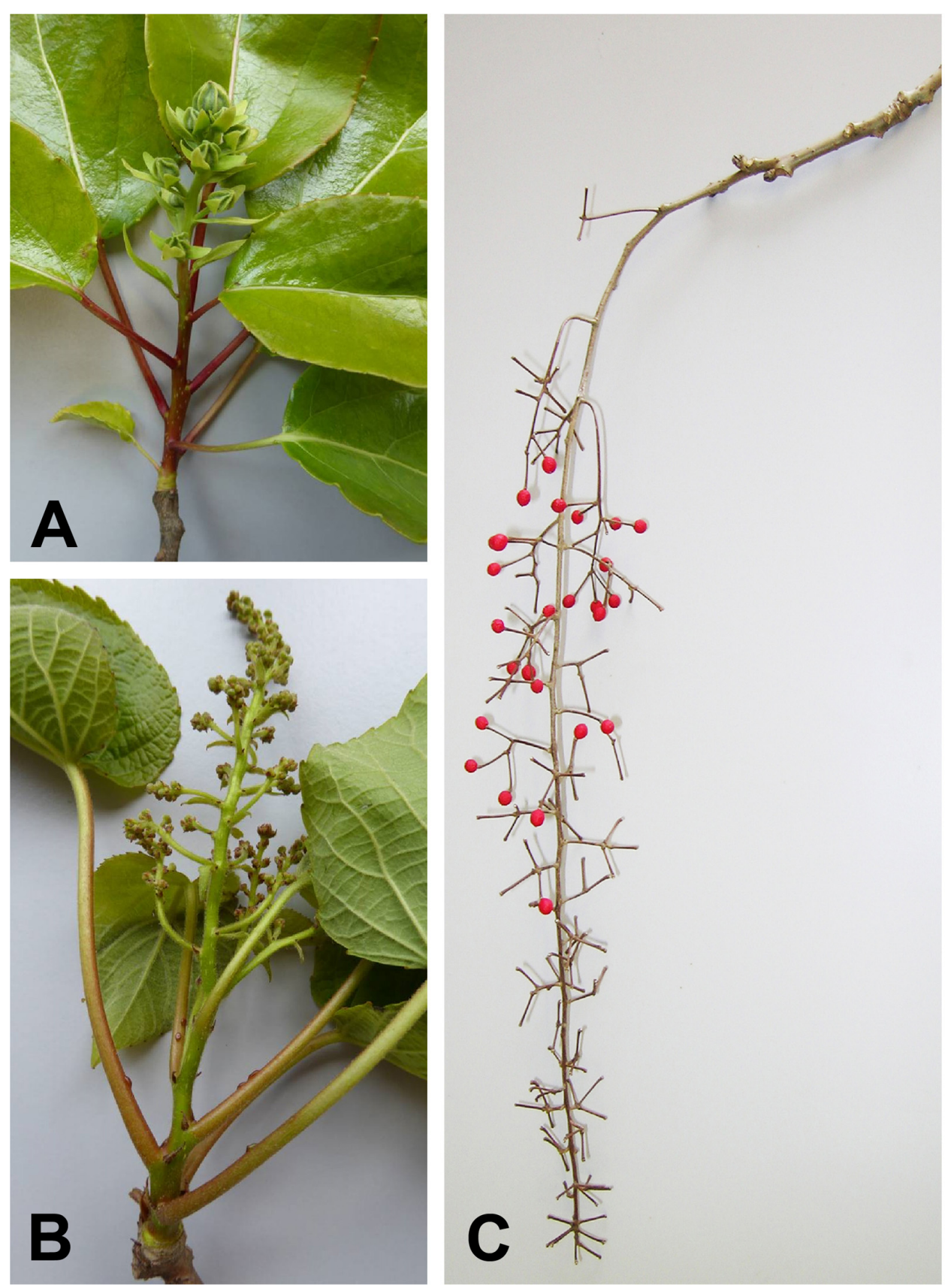

FIGURE 3 | Photographs of inflorescences. (A) Young inflorescence of Carrierea calycina Franch.) collected May 2015. The flowers are unopened. The floral bracts and calyces are visible. (B) Young male inflorescence of Idesia polycarpa Maxim., collected May 2015. The flower buds are still small but the branching of the paniculate inflorescence is evident. This inflorescence has developed in 3 months from an inflorescence meristem as shown in Figure 5B. (C) Previous year's female inflorescence (infructescence) of I. polycarpa, collected February 2015, showing the extensive branching of the inflorescence.

bracts are therefore simply homologous with the floral bracts of other members of the salicoid clade.

All genera have a calyx of (3-)5(-6) sepals, except Salix and Populus which lack an obvious perianth entirely. It should be noted that in Olmediella the calyx is reduced and quickly caducous (Alford, 2005). The staminate flowers have numerous stamens (in all except Salix, which generally has only 1-5 stamens) and a vestigial ovary (absent in Salix and Populus). The pistillate flowers have numerous small staminodes (except Populus and Salix). The presence of vestigial sexual organs in most species but their complete absence in Salix and Populus indicates the extent of the process of floral reduction in those genera. However, it is not known whether the developmental pathways for vestigial pistils in males (and staminodes in females) 
has been completely removed as part of sex determination or merely reduced to the extent it no longer has anatomical consequence.

The nectarial disk glands are an important floral feature in many genera (Table 1). These glands are generally assumed to be outgrowths of the disk. However, they are consistently associated with the stamens and staminodes, appearing interspersed among the stamens (intrastaminal, as in Idesia), or at the bases of the stamens in Olmediella (Alford, 2005). This location raises the question of whether they might be staminodial in origin.

There is a further question of whether the disk glands (nectaries) of Salix are homologous with the disk glands of other genera. Fisher has argued convincingly (Fisher, 1928a,b) that they represent a modified perianth because there appears to be some vascularization. However, Fisher made this argument before the outgroups of Salix were known. Now that we know the close relationship between Salix and other genera with disk glands, it seems logical to assume their homology (Alford, 2005).

Another puzzle is the "cupular disk" of Populus. Fisher homologised this structure with perianth and with the disk glands of Salix: "The disk-shaped perianth of Populus, or its peripheral parts, is homologous with the nectary of Salix" (Fisher, 1928b). Skvortsov (1999) also had no difficulty homologizing the disk glands of Salix with the cupular disk of Populus, mainly because the disk glands in Salix are sometimes united and approach in morphology the cupular disk of Populus. He writes: [Salix has] “...one or two (or a few) nectariferous glands, which occasionally are connate into a lobed glandular disk. These glands are obviously homologous to the cup-shaped disk in the poplars (which is sometimes called perianth)." However, the cupular disk of Populus is vascularized, consistent with Fisher's thesis that the disk glands of Salix have a perianth origin, assuming the two to have a common origin. However, it is also possible that as non-perianth disk glands evolved to increased complexity, vascularization was co-opted. Another possibility is that the cupular disk of Populus is indeed directly homologous with the calyx but not with the glands of Salix (which then have a nonperianth origin). Finally, the simplest explanation of all is that the cupular disk is merely an enlarged disk (i.e., receptacular in origin).
In this paper we seek to investigate whether the morphology of closely related non-catkin-bearing species can inform our understanding of the evolution of catkins in the Salicaceae. In particular we are interested in setting out the main ways in which Salix and Populus differ, in reproductive morphology and phenology, from their close relatives. Knowledge of the inflorescence morphology and flowering behavior of related plants allows the formulation of scenarios by which catkins evolved in this clade.

\section{MATERIALS AND METHODS}

\section{Sample Collection}

For Idesia, Carrierea, and Poliothyrsis, terminal resting buds were collected in spring before bud-break. In Salix and Populus lateral inflorescence buds were collected at the same time. A young inflorescence of Olmediella was collected at the same time from greenhouse-grown material. After budbreak young inflorescence shoots were also examined. A list of samples collected with accession numbers is given in Table 2.

\section{Sample Preparation}

Collections of inflorescence material were killed and fixed in formalin-acetic acid-alcohol (FAA) for approximately 1 week followed by storage in $70 \%$ ethanol. Some material was dehydrated through an ethanol series to $100 \%$ ethanol, transferred to Histoclear before embedding in Paraplast using standard protocols. The wax blocks were sectioned at $10 \mu \mathrm{m}$ thickness on a rotary microtome (Leica RM2155) and the resulting sections were stained in $0.5 \%(\mathrm{w} / \mathrm{v})$ solution of toluidine blue before mounting on microscope slides in DPX mountant. Images were captured using a Zeiss Axiocam HRc camera attached to a Leica DMLB microscope.

Other material was dehydrated through an alcohol series into acetone and transferred to a critical-point drier (Tousimis Autosamdri 815B). Dried material was then sputter-coated with platinum in a sputter coater (Emitech K550). The material was examined on a Hitachi S-4700 II cold-field emission scanning electron microscope.

TABLE 2 | Details of material examined in this study.

\begin{tabular}{|c|c|c|}
\hline Name & RBG Kew accession no. & Date collected \\
\hline Carrierea calycina Franch. -F & $2006-616$ & $6.2 .2015,13.2 .2015$ \\
\hline Idesia polycarpa Maxim. - F & $2006-332$ & $6.2 .2015,13.2 .2015$ \\
\hline Idesia polycarpa - M & $2008-416$ & $6.2 .2015,13.2 .2015$ \\
\hline *Olmediella betschleriana (Göpp.) Loes. - F & $1969-12335$ & 16.2 .2015 \\
\hline *Poliothyrsis sinensis Oliv. - Mon & 1973-20904 & $7.2 .2015,13.2 .2015$ \\
\hline Populus nigra L. - M & 1988-8331 & 2.2.2015 \\
\hline Populus purdomii Rehder - F & $1973-6401$ & 2.2 .2015 \\
\hline Populus wilsonii C.K. Schneid. - F & $1979-1110$ & 18.2 .2015 \\
\hline Salix miyabeana Seem. - M & $1999-547$ & 16.2 .2015 \\
\hline Salix sp. - F & $1999-548$ & 16.2 .2015 \\
\hline
\end{tabular}

All material was collected from living material growing in the Royal Botanic Gardens Kew. Male and female plants are indicated as M and F, respectively (Mon, monoecious). An asterisk indicates those species not figured in the present study. 


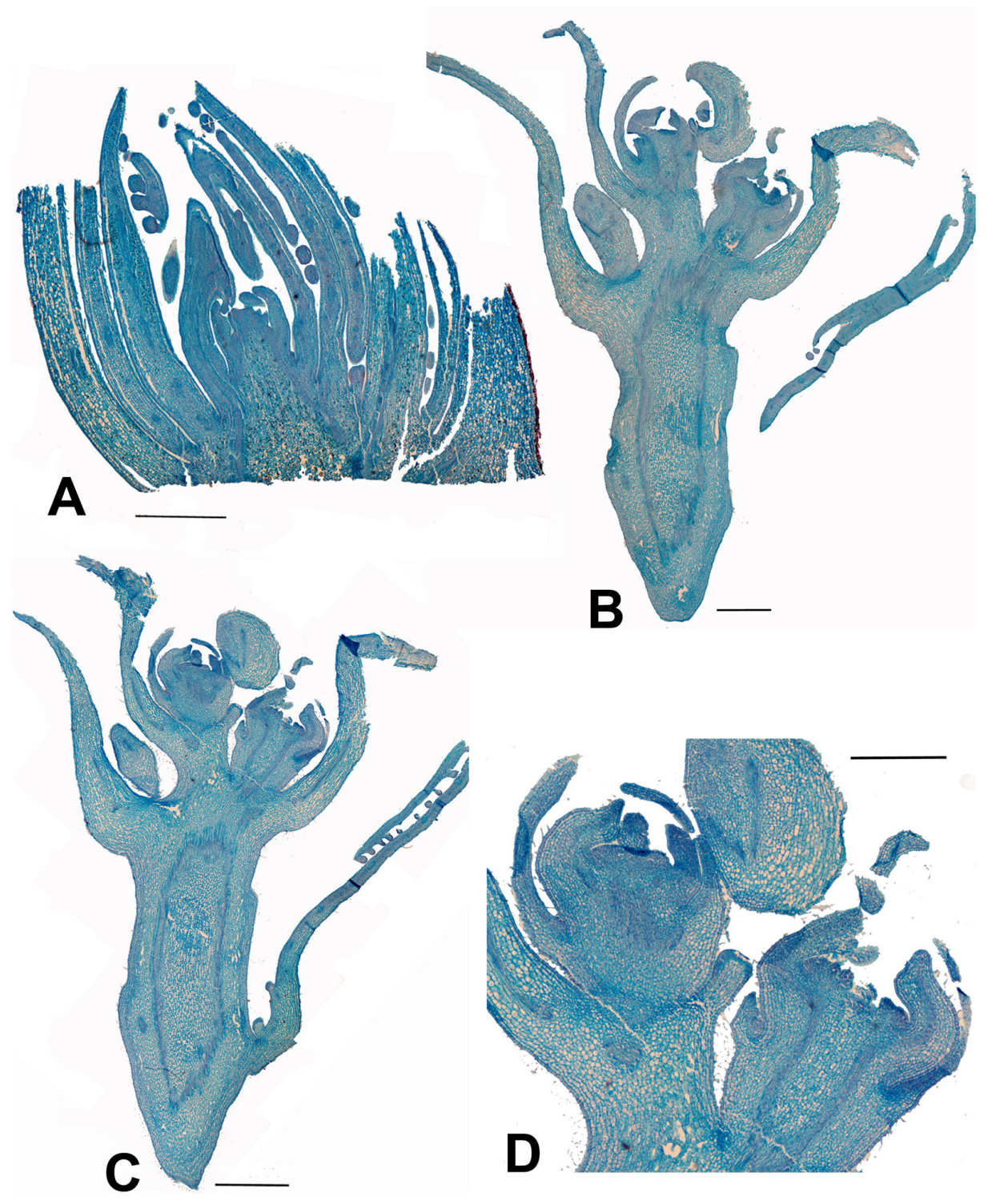

FIGURE 4 | Carrierea calycina. (A) Over-wintering bud with minute inflorescence meristem surrounded by protective bracts (bud scales) collected 13th February 2015. At this stage the inflorescence has not started developing. (B,C) Sequential longitudinal sections of dissected resting bud (pre-budbreak) collected 2 nd April 2015, showing a fairly well-developed inflorescence with individual flowers differentiated. Floral bracts and calyx are visible but other organs have not formed and gender is not visible at this stage (bud scales removed). (D) Detail of developing flower from (C). Scale bars $=1 \mathrm{~mm}$.

\section{RESULTS}

\section{Phenology and Gross Morphology of Reproductive Shoots}

In autumn Poliothyrsis, Idesia, and Carrierea set comparatively large terminal buds on all shoots of the previous year. The majority of these buds produce short shoots terminating in an inflorescence (Figure 3). Vegetative growth (and flowers of the following year) is therefore left to side shoots. This growth pattern corresponds with the "Modèle de Leeuwenberg" of Hallé and Oldeman (Hallé et al., 1978). Populus has the opposite tendency, with terminal buds tending to be vegetative and side shoots (from axillary buds of the previous year) tending to contain catkins. In Poliothyrsis, nearly all growth is by terminal buds from side shoots of the previous year, these in turn terminate in inflorescences with between four and six leaves below then. In Carrierea there tend to be four to six leaves below each inflorescence and in Idesia four to five.

\section{Developmental Anatomy}

Carrierea (Figures 4A-D) and Idesia (Figures 5A,B) show very little development of the inflorescence when collected in February. In contrast, Populus and Salix (Figures 6 and 7) have fully formed flowers. The preformation and early development 

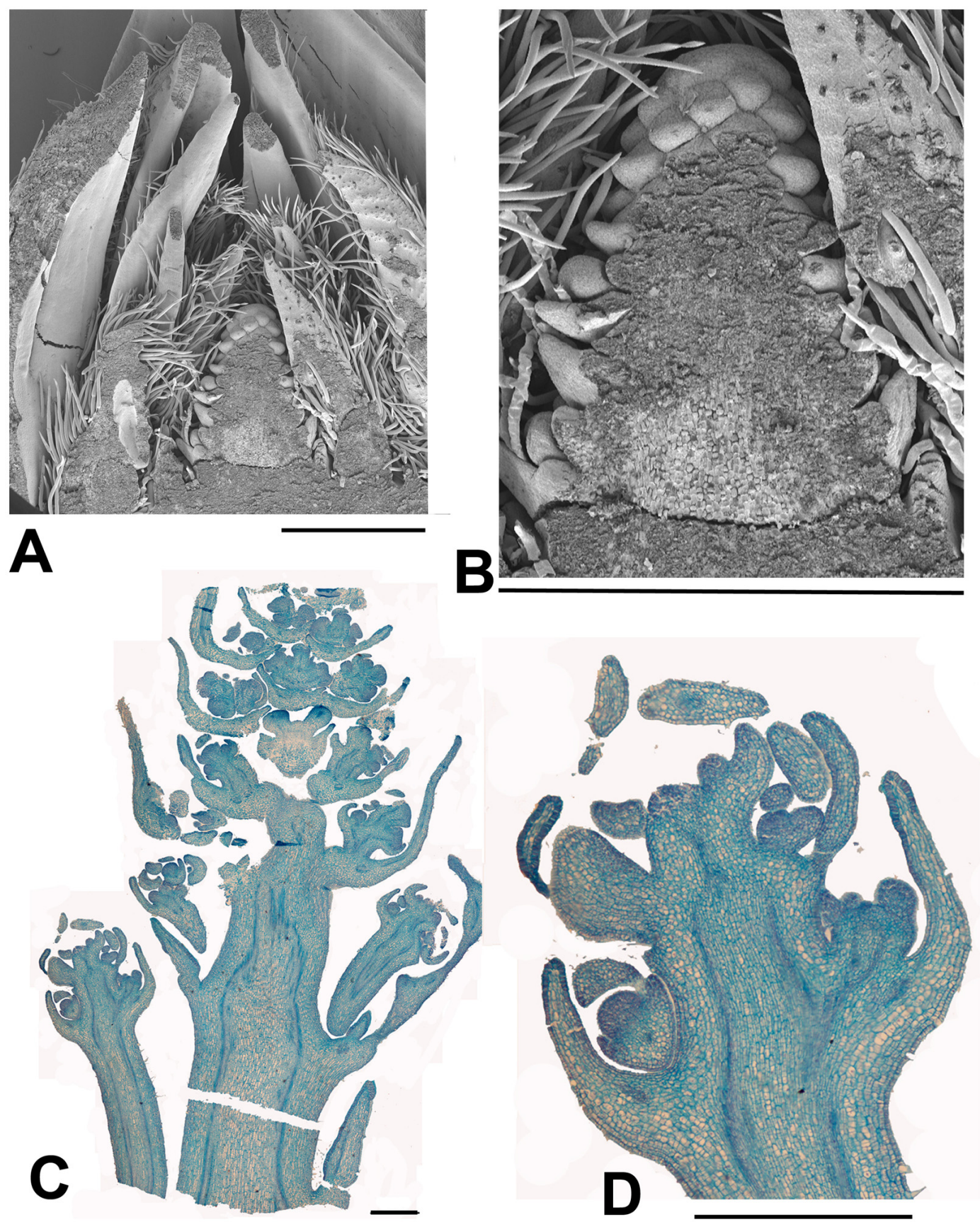

FIGURE 5 | Idesia polycarpa. (A) SEM of bisected over-wintering bud collected 13th February 2015 showing an inflorescence meristem surrounded by protective bracts (bud scales; B) Detail of (A) showing just the inflorescence meristem, At this stage the inflorescence meristem shows inflorescence bract primordia but not floral primordia. Later branch primordia will form in the axils of the inflorescence bracts and develop into the paniculate (i.e., branched) inflorescence. At the same stage Salix and Populus inflorescences are fully developed with completely formed flowers (Figures $\mathbf{6}$ and 7). (C) Longitudinal section of dissected over-wintering (pre-budbreak) bud collected 2nd April 2015 showing development of panicle (bud scales removed). Flowers can be seen in early development, with some development of the calyx but not other organs. At the same date Salix and Populus have finished flowering. (D) Enlarged portion of (C). Scale bars $=1 \mathrm{~mm}$.

of inflorescences in Populus and Salix is well known, with inflorescences formed the previous year (Boes and Strauss, 1994; Kaul, 1995; Brunner et al., 2014). Figures 6 and 7 show the almost fully developed flowers inside the unopened buds enclosing catkins of Populus and Salix when sampled in early
February (well before bud opening and flowering in March). In contrast, developmental timing in Idesia was found to be very different. No identifiable inflorescence meristems were found in buds sampled in February, although well-developed leaf primordia were present (Figure 5). Resampling in April revealed 


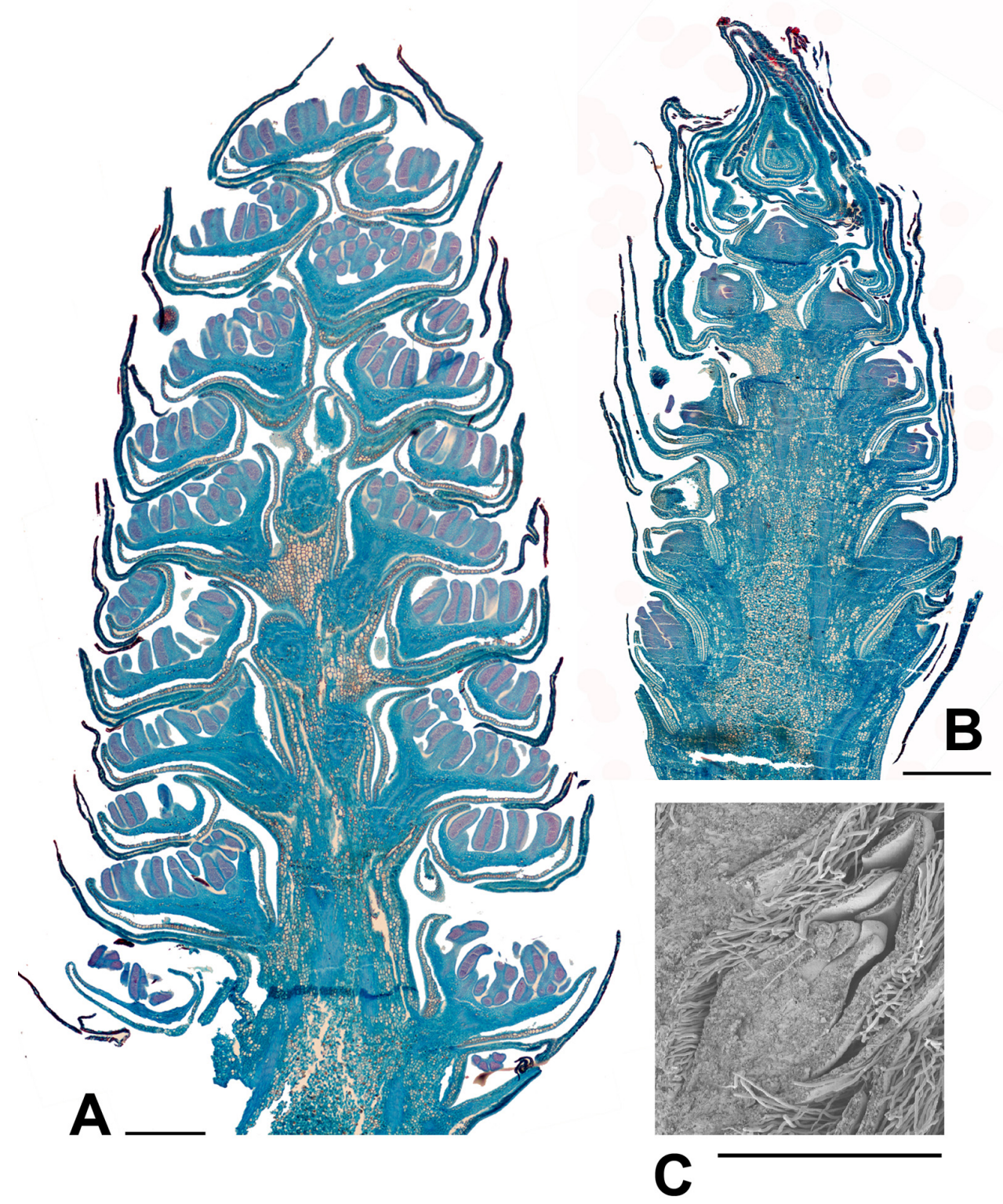

FIGURE 6 | Populus. (A) Populus nigra L., male inflorescence (catkin) with nearly fully developed flowers. Longitudinal section of catkin, collected 2nd February 2015, showing well-developed stamens with short filaments and longer anthers with red-staining developing pollen (bud scales removed). (B) P. purdomii Rehder, female inflorescence with flowers in a late stage of development. Longitudinal section of catkin collected 2nd February 2015, showing single ovary per flower.

(C) P. wilsonii C.K.Schneid., SEM detail showing a well developed ovary from a female inflorescence, collected 2nd February 2015. Scale bars $=1 \mathrm{~mm}$. Bud scales removed.

dramatic differences. A well-developed inflorescence meristem was found to be present, but no developed flowers (Figure 5). We conclude that inflorescence development in Idesia occurs in response to warming temperatures in the spring, although much of it is completed within the closed bud before bud break in May. At an early stage, the inflorescence meristem resembles a catkin in having numerous spirally arranged bracts and primordia on an axis. However, these primordia will develop into inflorescence branches and not individual flowers.

\section{DISCUSSION}

\section{Evolutionary-developmental}

Mechanisms Implicated in Inflorescence Evolution in the Salicoid Clade of

\section{Salicaceae}

When the highly reduced and specialized inflorescence of Salix (Figure 7) is compared with its outgroup genera, for instance Idesia (Table 3), there are several traits that are shared. Our 


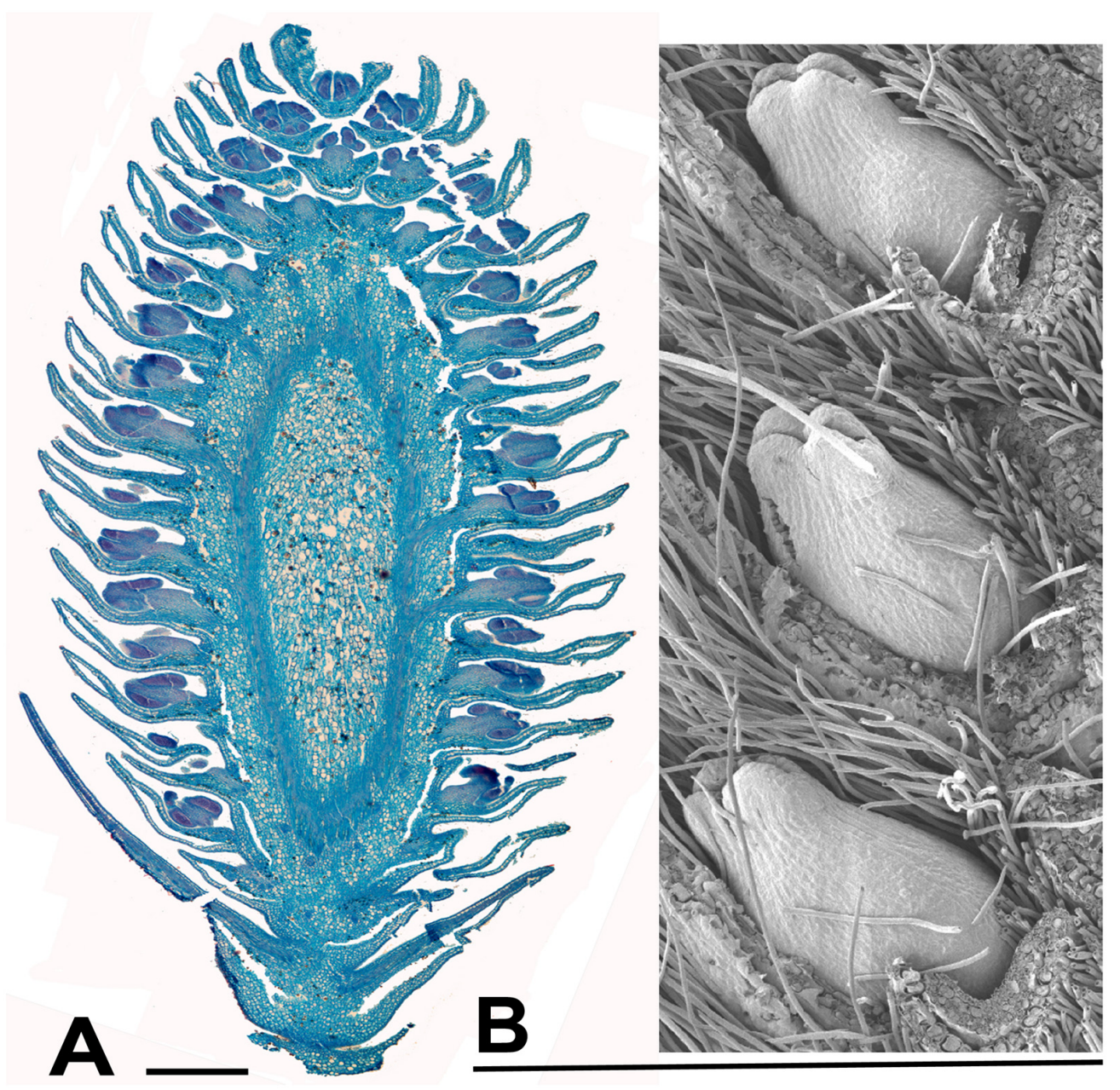

FIGURE 7 | Salix. (A) Salix miyabeana Seem., male inflorescence (catkin). Longitudinal section of over-wintering bud (bud scales removed), collected 16th February 2015, showing well-developed flowers, each with an apparent single stamen (actually two stamens completely united except at the anther). The anthers are well differentiated pre-anthesis. (B) Salix sp., SEM showing three well developed female flowers in the axils of bracts, from an inflorescence in over-wintering bud collected 16th February 2015. Scale bars $=0.5 \mathrm{~mm}$. Bud scales removed.

comparative investigation indicates that these apparently preexisting shared traits (unisexual flowers, dioecy and association of flowering with resting buds) likely pre-date the evolution of catkins rather than being a consequence of the evolution of catkins. In contrast to the monoecious Fagales, where typically male and female catkins occur on the same tree, dioecy is universal in the catkin-bearing Salicaceae and their immediate relatives. Although bisexual teratomorphs are sometimes found, bisexual species in the catkin-bearing Salicaceae are exceedingly rare, although they do occur as a derived condition (Rohwer and Kubitzki, 1984). Dioecy in the group is ancient and stable and under genetic control (Geraldes et al., 2015), even though the genetic mechanism is labile and has apparently undergone numerous shifts within the genome (Filatov, 2015; Geraldes et al., 2015).

A number of other traits, however, are specific to the catkin-bearing habit: preformation, precocity, bud dimorphism, inflorescence contraction, floral reduction, lateralization. These traits represent necessary steps to the evolution of catkins in the Salicaceae. They will be discussed in turn.

\section{Preformation}

This is the formation of structures a long time before they become visible or functional. In Salix and Populus the inflorescence is initiated as soon as the resting buds form, which may be as early as May in the year preceding flowering. The early initiation allows time for the catkin to be fully formed by the time buds break in the spring. By contrast, other members of the salicoid clade complete inflorescence maturation only after bud break in the spring (contrast Figures 5A,B with Figures 6 and 7). Inflorescence development may start in the bud (partial preformation) but completes on the growing shoot (see results and Figure 5). Preformation is obviously a necessary precondition for precocity (below), and precocity may be what is driving full preformation. Preformation in resting buds involves a paradox. In a normal bud there is no leaf production and shoot growth has ceased. The bud 
is in developmental stasis, at least vegetatively, in preparation for full dormancy. On the other hand with floral preformation there is much reproductive development in the bud with the formation of an inflorescence meristem and floral primordia and their development into flowers. The evolution of preformation implies increased developmental control in coupling two phase changes of the meristem: change from active growth to dormancy and change from vegetative to reproductive. In Idesia these phase changes seem to occur sequentially, first dormancy then inflorescence formation. In poplar and willow they appear to be coupled.

\section{Precocity}

The term precocity is here applied to the breaking of reproductive buds before the vegetative buds to allow flowering before the development of a canopy. It should be noted that precocity as discussed here is seasonal precocity, not flowering as a juvenile (also sometimes refers to as precocious flowering). Seasonal precocity implies bud dimorphism (below). Although most willows are strictly precocious, the genus Salix as a whole shows a great deal of variation in this trait. Some are what salicologists call "coetaneous" (an archaic word for contemporaneous), meaning that the catkins are produced at the same time (contemporaneously) with the leaves. More precisely this means that the catkins are not sessile on the previous years growth but on, bud-break, a leafy shoot is produced which the catkin terminates. In this respect it is directly analogous with Idesia, in which the inflorescence terminates a short leafy shoot. A third type of reproductive behavior, "serotiny" (from the latin serotinus $=$ coming late), also occurs in willows. This is an extreme form of the coetaneous habit. In botany serotiny is more commonly applied to delayed seed dispersal, but in willows it refers to delayed flowering. This occurs when catkins are poorly developed in bud and complete their development postbudbreak, thus apparently flowering with the current season's growth. Although formal analyses are lacking (partly due to continuing uncertainty over the phylogeny of Salix), it is likely

TABLE 3 | Comparison of Idesia and Salix in terms of putative processes and characteristics of inflorescence evolution and development.

\begin{tabular}{lll}
\hline Process/characteristic & Idesia & Salix \\
\hline Unisexual flowers & Yes & Yes \\
Dioecy & Yes & Yes \\
Flowering linked to resting buds & Yes & Yes \\
Preformation & No (or short) & Yes (long) \\
Contraction & No (elongated & Yes (complete) \\
& branched rachis) & \\
Non-terminal deletion & No & Yes (in most \\
& & species) \\
Precocity & No & Yes \\
Bud dimorphism & No (buds producing & Yes (buds either \\
& leaves and & vegetative or \\
Floral reduction & inflorescence) & flowering) \\
Lateralization & No & Yes \\
& No (inflorescence & Yes (inflorescence \\
& terminal) & lateral)
\end{tabular}

that coetaneous and serotinous willows are derived and may represent reversals. However, if the coetaneous habit is found to be primitive in Salix it provides a link to other genera of the salicoid clade.

\section{Non-terminal Deletion}

Closely associated with precocity, non-terminal deletion is the evolutionary loss of parts of an organ from the base rather than the tip. In this case, it refers to the loss of leaves below the terminal inflorescence, as in precocious Salix and Populus. For instance Idesia bears its inflorescences on leafy shoots whereas the catkins of Populus are not associated with vegetative leaves. Evolutionary loss at the end of a shoot may simply be the consequence of growth ceasing early, while evolutionary gain at the tip may be the result of growth continuing for a longer period. Loss (in this case of leaves) at the base of a shoot is more problematic. It requires that a late developmental program (in this case inflorescence production) is brought forward to replace early developmental programs (in this case leaf primordia production which would normally take place as the resting buds form). The concepts of terminal and non-terminal deletion have been used in evolutionary analyses of other botanical systems, including of fossils (Bateman, 1994). In our present system we can see that extreme inflorescence preformation, characteristic of Populus and Salix, brings forward inflorescence production to precisely the time when leaves would be forming during the development of the resting bud. Therefore precocity, preformation and nonterminal deletion, although separate concepts, may in fact be interlinked parts of a single evolutionary scenario.

\section{Bud Dimorphism}

In Salix and Populus there is a functional dimorphism between floral and vegetative buds. Precocity implies that floral and vegetative buds may have different temperature sensitivity, with inflorescence buds having a lower cumulative temperature requirement (heat sum, for instance in degree days) required for development. Bud dimorphism allows a marked "division of labor" between reproductive and vegetative meristems. In poplar and willow the catkin usually has no vegetative function whatsoever, and correspondingly the vegetative shoot has no reproductive function. In Idesia the distinction is blurred. Almost all shoots produce not only a terminal inflorescence but also numerous leaves below the inflorescence. Thus reproductive and vegetative functions are carried out by the same buds (reprovegetative buds).

\section{Contraction}

In most genera of the salicoid clade the inflorescence is a lax branched panicle with elongated rachises. The evolution of the catkin therefore requires evolutionary and developmental contraction of the inflorescence. The inflorescence meristem of Idesia, with primordia and associated bract primordia (Figure 5) gives a possible scenario of how the catkin could have evolved. The primordia would normally develop into panicle branches and then into flowers. If the floral developmental pathway were to be brought forward in developmental time then it is possible to see how the result would be a series 
of bract associated flowers. This would be an example of heterochrony: a change in developmental timing (Bateman, 1994; Rudall and Bateman, 2004). In Solanaceae, it is suggested that minor changes in the maturation process of apical meristems can give rise to dramatic changes in reproductive shoot organization (Park et al., 2012, 2014). In grasses, more complex panicles can be formed by delaying the phase change from the indeterminate shoot meristem (SM) inflorescence building program to a determinate spikelet and floral meristem (FM) program (Kyozuka et al., 2014). In the evolution of catkins we propose the reverse: a simplification of the panicle by early phase change from an inflorescence building (SM) program to a determinate FM developmental program. It is of interest that Fisher (Fisher, 1928a,b) found, in the catkins of some species of Salix, microstructures that she interpreted as the vestigial branches of an ancestral branched inflorescence. This implies that catkin evolution proceded via a progressive shortening of axes rather than a complete deletion of the branching pathway for inflorescence development. Furthermore, the floral developmental pathway has not been brought forward so far as to eliminate all trace of branch structure. Fisher's finding was all the more remarkable as it came long before the appropriate outgroups were known and it was easy to assume that the ancestral form was a simple raceme rather than a branched panicle.

\section{Floral Reduction}

Small flowers are an obvious consequence of the evolution of the catkin as there is no space for elaborate flowers in a highly condensed inflorescence. Additionally some of the functions of individual flowers are, in the catkin, taken over by the inflorescence as a whole. An example is floral protection in bud which is done by the calyx in Idesia but by the tight packing of the flowers and investing bracts in poplar and willow. A remaining question is whether the calyx has been lost completely or converted into disk glands (nectaries) in willow. For nearly a century this question has been considered closed with the consensus that the disk glands of willow and the cupular disk of poplar represent the lost perianth. However, the recent identification of the relatives of Salix and Populus followed by the realization that they have both disk glands and a calyx have cast some doubt on this consensus (Alford, 2005). In addition to the loss of calyx there has also been a reduction in stamens in the insect-pollinated Salix (down to one in some species). In the wind-pollinated Populus, large numbers of stamens have been retained, packed very tightly into the flowers in bud. This illustrates the constraint that the more pollen-wasteful process of wind pollination places on floral reduction in poplar.

\section{Lateralization}

In Idesia, the terminal buds on shoots produce inflorescences and the inflorescence terminates shoot growth. In poplar, terminal buds are never (or at least very rarely) reproductive. The catkin buds are all lateral (axillary) buds. The determinate growth of all terminal buds puts a constraint on the rate of height growth that can be attained by Idesia and its relatives which tend to be relatively small trees. Poplar, however, because its inflorescences are lateral, can maintain indeterminate growth, resulting in poplars being generally the fastest growing and tallest dicotyledonous trees in the northern hemisphere. Catkins are also lateral in willow, but in willow the terminal shoot tends to abort rather than form a resting bud for continued growth the following year, hence willows also tend to be smaller in stature. In the Juglandaceae, lateralization of the catkins is only partial, as while staminate catkins are general lateral, pistillate catkins are usually terminal (Manning, 1938). This could suggest a physiological constraint between investment in large fruit (as in Juglandaceae) and inflorescence position.

\section{Adaptive Significance of Inflorescence Evolution in Salicaceae}

The compactness of the catkin allows inflorescence development to be completed within the inflorescence bud. This in turn allows for precocious flowering. Precocity has an obvious consequence for wind-pollinated plants (such as poplars, Populus) as it allows flowers to be pollinated before the emergence of the leafy canopy which may attenuate air movement among the branches. For insect-pollinated plants, precocity effectively removes competition for bees from other flowers. Willows (Salix) are generally insect pollinated (Karrenberg et al., 2002), particularly by bees of the genus Andrena (Knuth, 1909; Ostaff et al., 2015). They are also well known to be an important source of pollen and nectar for honey bees (Apis mellifera L.) early in the year when bees have few other food sources. However, a trade-off against the absence of competition for pollinators, is the fact that there may be fewer bees flying in early months of the year. This mechanism, of course, applies only to temperate regions with a pronounced cold season, and is not applicable to catkin-like inflorescences of tropical origin such as the related Lacistemataceae.

Another mechanism, related to precocity, is thermal protection (Tsukaya and Tsuge, 2001). The contraction of the flowers into a compact inflorescence allows the flowers to be protected by hairs on the margins of the bracts. These form, in some instances, a striking wooly insulating layer around the catkin. Indeed, the name 'catkin' alludes to this flocculence. The woolliness is equivalent to the wooly hairs of many alpine plants and by trapping air may allow flowers to survive the severe night frosts encountered as a consequence of precocity. A lax panicle, on the other hand, cannot be protected by hairs on its bracts.

A third mechanism that should be considered is reproductive efficiency. Poplars and willows produce large amounts of seed with little investment in inflorescence structures. Compare this with Idesia, which produces a modest amount of seed with a heavy investment in inflorescence rachis and flower stalks. Furthermore, individual flowers of Idesia are large. They have to be, as each one has to provide a sufficient landing surface for pollinating insects. By aggregating minute flowers together, Salix provides a landing platform for bees while minimizing investment in individual flowers. This is an example of synorganization, i.e., the provision of a novel or more efficient function by different plant organs working in concert, in this 
case numerous small flowers organized into a larger unit that can function as a landing surface.

\section{The Genome-enabled Family Salicaceae as a Promising System for Evolutionary Developmental Biology}

The salicoid clade of the Salicaceae exhibits a promising range of ecologically important morphological traits (Cronk, 2005). It is also one of the best characterized clades of dicotyledons at the genome level. The poplar ( $P$. trichocarpa Torr. \& A.Gray) genome was the third plant genome to be released (Tuskan et al., 2006) and it has now been joined on the comparative genomics site Phytozome (Goodstein et al., 2012) by the genome of Salix purpurea L., an economically important basket and biofuel willow extensively used in breeding programs for crossing with other species. Complete genome sequencing projects are well advanced for other species of Salix and Populus and a plethora of genomic information will soon be available. This raises the possibility of a molecular approach to the evolution of many key traits in the salicoid clade, including inflorescence architecture. Importantly for reproductive traits, the genomic architecture of the sex locus in $P$. trichocarpa has recently been elucidated (Geraldes et al., 2015).

Inflorescence architecture is a economically important trait in many crop species. The grapevine (Vitis) is a good example, in which a compact or lax infructescence (caused by variation of rachis length) is a characteristic of commercial importance (Correa et al., 2014). For obvious reasons the genes underlying this trait are now attracting increased attention. A number of mutants are known in Arabidopsis that affect inflorescence traits. An example of genes of potential relevance to catkins are the compact inflorescence (CFL) genes (Goosey and Sharrock, 2001).

The rich genomic resources developing for Salix and Populus will greatly facilitate the development of genomic resources for other genera in the salicoid clade. A complete genome of Idesia would be particularly valuable as an outgroup for Salix and Populus. Similarly, a member of the Salicaceae that is more distant (such as Azara) would be useful as an outgroup for the salicoid clade as a whole. Azara is outside the palaeopolyploidy event

\section{REFERENCES}

Alford, M. (2005). Systematic Studies in Flacourtiaceae. Ph.D. thesis, Cornell University, Ithaca, NY.

Alford, M. H., Brantley, R. J., Hernández, C. L., and Samarakoon, T. (2009). "What are the closest relatives of Salix and Populus?," in Abstracts - Botany and Mycology 2009 (Snowbird, UT: Botanical Society of America).

Angiosperm Phylogeny Group (2009). An update of the Angiosperm Phylogeny Group classification for the orders and families of flowering plants: APG III. Bot. J. Linn. Soc. 161, 105-121. doi: 10.1016/j.jep.2015.05.035

Bateman, R. M. (1994). Evolutionary-developmental change in the growth architecture of fossil rhizomorphic lycopsids - scenarios constructed on cladistic foundations. Biol. Rev. 69, 527-597. doi: 10.1111/j.1469185X.1994.tb01249.x

Boes, T. K., and Strauss, S. H. (1994). Floral phenology amd morphology of black cottonwood, Populus trichicarpa (Salicaceae). Am. J. Bot. 81, 562-567. doi: $10.2307 / 2445730$ that has occurred in the salicoid clade, it would therefore be particularly useful to assess evolution of gene paralogues in Salix and Populus resulting from the whole genome duplication event.

\section{CONCLUSION}

The morphological richness of the Salicaceae coupled with the rapidly expanding genomic resources make this family, of all woody plant families, particularly promising for genome-enabled evolutionary developmental biology.

\section{AUTHOR CONTRIBUTIONS}

QC and PR planned the study, collected material, supervised the anatomical work and wrote the paper. IN carried out the anatomical work and photomicrography and contributed to writing the paper.

\section{FUNDING}

Funding for this study came from a Royal Society International Exchanges Scheme grant to PR and QC and from the Natural Sciences and Engineering Research Council of Canada (NSERC) Discovery Grants Program (grant no. RGPIN-2014-05820) grant to QC.

\section{ACKNOWLEDGMENTS}

We thank the staff of the Horticulture Directorate of the Royal Botanic Gardens, Kew for maintaining living collections of the plants studied here. We also thank Irina Belyaeva (RBG, Kew) and the journal reviewers for helpful comments on the manuscript. QC gratefully acknowledges appointments as Visiting Professor at Queen Mary University of London, and as Honorary Research Associate at the Royal Botanic Gardens, Kew, which greatly facilitated this work.

Boucher, L. D., Manchester, S. R., and Judd, W. S. (2003). An extinct genus of Salicaceae based on twigs with attached flowers fruits, and foliage from the Eocene Green River Formation of Utah and Colorado, USA. Am. J. Bot. 90, 1389-1399. doi: 10.3732/ajb.90.9.1389

Brunner, A. M., Evans, L. M., Hsu, C.-Y., and Sheng, X. (2014). Vernalization and the chilling requirement to exit bud dormancy: shared or separate regulation? Front. Plant Sci. 5:732. doi: 10.3389/fpls.201 4.00732

Chase, M. W., Zmarzty, S., Lledó, D., Wurdack, K., Swensen, S. M., and Fay, M. F. (2002). When in doubt, put it in Flacourtiaceae: a molecular phylogenetic analysis based on plastid rbcL DNA sequences. Kew Bull. 57, 141-181. doi: $10.2307 / 4110825$

Correa, J., Mamani, M., Munoz-Espinoza, C., Laborie, D., Munoz, C., Pinto, M., et al. (2014). Heritability and identification of QTLs and underlying candidate genes associated with the architecture of the grapevine cluster (Vitis vinifera L.). Theor. Appl. Genet. 127, 1143-1162. doi: 10.1007/s00122-014-2 286-y 
Cronk, Q. C. B. (2005). Plant eco-devo: the potential of poplar as a model organism. New Phytol. 166, 39-48. doi: 10.1111/j.1469-8137.2005.01369.x

Darlington, C. D., and Wylie, A. P. (1955). Chromosome Atlas of Flowering Plants. London: George Allen and Unwin Ltd.

Davis, C. C., Webb, C. O., Wurdack, K. J., Jaramillo, C. A., and Donoghue, M. J. (2005). Explosive radiation of malpighiales supports a mid-Cretaceous origin of modern tropical rain forests. Am. Nat. 165, E36-E65. doi: 10.1086/428296

Dodoens, R. (1578). A Niewe Herball, or Historie of Plantes. London: G. Dewes.

Du Mortier, B.-C. (1825). Verhandeling Over het Geslacht der Wilgen (Salix) en de Natuurlijke Familie der Amentaceae [Treatise on the Willow Genus, Salix and the Natural Family Amentaceae]. Amsterdam: J. van der Hey.

Eichler, A. W. (1883). Syllabus der Vorlesungen über Specielle und MedicinischPharmaceutische Botanik. Berlin: Gebrüder Borntraeger.

Fang, Z., Fang, C., and Skvortsov, A. K. (1999). "Salicaceae," in Flora of China, eds Z. Y. Wu and P. H. Raven (Beijing: Science Press), 162-274.

Filatov, D. A. (2015). Homomorphic plant sex chromosomes are coming of age. Mol. Ecol. 24, 3217-3219. doi: 10.1111/mec.13268

Fisher, M. J. (1928a). The morphology and anatomy of the flowers of the Salicaceae I. Am. J. Bot. 15, 307-326. doi: 10.2307/2435831

Fisher, M. J. (1928b). The morphology and anatomy of the flowers of the Salicaceae II. Am. J. Bot. 15, 372-394. doi: 10.2307/2435831

Geraldes, A., Hefer, C. A., Capron, A., Kolosova, N., Martinez-Nuñez, F., Soolanayakanahally, R. Y., et al. (2015). Recent Y chromosome divergence despite ancient origin of dioecy in poplars (Populus). Mol. Ecol. 24, 3243-3256. doi: $10.1111 /$ mec.13126

Goodstein, D. M., Shu, S. Q., Howson, R., Neupane, R., Hayes, R. D., Fazo, J., et al. (2012). Phytozome: a comparative platform for green plant genomics. Nucleic Acids Res. 40, D1178-D1186. doi: 10.1093/nar/gkr944

Goosey, L., and Sharrock, R. (2001). The Arabidopsis compact inflorescence genes: phase-specific growth regulation and the determination of inflorescence architecture. Plant J. 26, 549-559. doi: 10.1046/j.1365-313x.2001.01053.x

Grill, I. (1990). Beiträge zur Karyosystematik der Flacourtiaceae. Ph.D. dissertation, Universität Wien, Vienna.

Hallé, F., Oldeman, R. A. A., and Tomlinson, P. B. (1978). Tropical Trees and Forests - An Architectural Analysis. Heidelberg: Springer-Verlag.

Karrenberg, S., Kollmann, J., and Edwards, P. J. (2002). Pollen vectors and inflorescence morphology in four species of Salix. Plant Syst. Evol. 235, 181-188. doi: $10.1007 / \mathrm{s} 00606-002-0231-z$

Kaul, R. B. (1995). Reproductive structure and organogenesis in a cottonwood, Populus deltoides (Salicaceae). Int. J. Plant Sci. 156, 172-180. doi: $10.1086 / 297238$

Knuth, P. (1909). Handbook of Flower Pollination: Based upon Hermann Müller's Work 'The Fertilisation of Flowers by Insects', Vol. 3. Oxford: Clarendon Press.

Korotkova, N., Schneider, J. V., Quandt, D., Worberg, A., Zizka, G., and Borsch, T. (2009). Phylogeny of the eudicot order Malpighiales: analysis of a recalcitrant clade with sequences of the petD group II intron. Plant Syst. Evol. 282, 201-228. doi: 10.1007/s00606-008-0099-7

Kyozuka, J., Tokunaga, H., and Yoshida, A. (2014). Control of grass inflorescence form by the fine-tuning of meristem phase change. Curr. Opin. Plant Biol. 17, 110-115. doi: 10.1016/j.pbi.2013.11.010

Leskinen, E., and Alstrom-Rapaport, C. (1999). Molecular phylogeny of Salicaceae and closely related Flacourtiaceae: evidence from 5.8 S, ITS 1 and ITS 2 of the rDNA. Plant Syst. Evol. 215, 209-227. doi: 10.1007/BF00984656
Manchester, S. R., Judd, W. S., and Handley, B. (2006). Foliage and fruits of early poplars (Salicaceae: Populus) from the eocene of Utah, Colorado, and Wyoming. Int. J. Plant Sci. 167, 897-908. doi: 10.1086/503918

Manning, W. E. (1938). The morphology of the flowers of the Juglandaceae. 1. The inflorescence. Am. J. Bot. 25, 407-419. doi: 10.2307/2436415

Ostaff, D. P., Mosseler, A., Johns, R. C., Javorek, S., Klymko, J., and Ascher, J. S. (2015). Willows (Salix spp.) as pollen and nectar sources for sustaining fruit and berry pollinating insects. Can. J. Plant Sci. 95, 505-516. doi: 10.4141/cjps2014-339

Park, S. J., Eshed, Y., and Lippman, Z. B. (2014). Meristem maturation and inflorescence architecture-lessons from the Solanaceae. Curr. Opin. Plant Biol. 17, 70-77. doi: 10.1016/j.pbi.2013.11.006

Park, S. J., Jiang, K., Schatz, M. C., and Lippman, Z. B. (2012). Rate of meristem maturation determines inflorescence architecture in tomato. Proc. Natl. Acad. Sci. U.S.A. 109, 639-644. doi: 10.1073/pnas.1114963109

Rohwer, J., and Kubitzki, K. (1984). Salix martiana, a regularly hermaphrodite willow. Plant Syst. Evol. 144, 99-101. doi: 10.1007/BF00986668

Rudall, P. J., and Bateman, R. M. (2004). Evolution of zygomorphy in monocot flowers: iterative patterns and developmental constraints. New Phytol. 162, 25-44. doi: 10.1111/j.1469-8137.2004.01032.x

Sanders, R. W., Stuessy, T. W., and Rodriguez, R. (1983). Chromosome numbers from the flora of the Juan Fernandez Islands. Am. J. Bot. 70, 799-810. doi: $10.2307 / 2442929$

Skvortsov, A. K. (1999). Willows of Russia and Adjacent Countries. Taxonomical and Geographical Revision. Joensuu: Joensuu University.

Sleumer, H. O. (1980). Flacourtiaceae. Flora Neotropica Monograph 22. New York, NY: New York Botanical Garden.

Sterck, L., Rombauts, S., Jansson, S., Sterky, F., Rouze, P., and Van De Peer, Y. (2005). EST data suggest that poplar is an ancient polyploid. New Phytol. 167, 165-170. doi: 10.1111/j.1469-8137.2005.01378.x

Stern, W. L. (1973). Development of the amentiferous concept. Brittonia 25, 316-333. doi: 10.2307/2805638

Tsukaya, H., and Tsuge, T. (2001). Morphological adaptation of inflorescences in plants that develop at low temperatures in early spring: the convergent evolution of "downy plants." Plant Biol. 3, 536-543. doi: 10.1055/s-200 $1-17727$

Tuskan, G. A., Difazio, S., Jansson, S., Bohlmann, J., Grigoriev, I., Hellsten, U., et al. (2006). The genome of black cottonwood, Populus trichocarpa (Torr. \& Gray). Science 313, 1596-1604.

Yang, Q., and Zmartzty, S. (2007). "Flacourtiaceae," Flora of China: Clusiaceae through Araliaceae, Vol. 13, eds Z. Wu and P. H. Raven (Beijing: Science Press), $112-138$.

Conflict of Interest Statement: The authors declare that the research was conducted in the absence of any commercial or financial relationships that could be construed as a potential conflict of interest.

Copyright (c) 2015 Cronk, Needham and Rudall. This is an open-access article distributed under the terms of the Creative Commons Attribution License (CC BY). The use, distribution or reproduction in other forums is permitted, provided the original author(s) or licensor are credited and that the original publication in this journal is cited, in accordance with accepted academic practice. No use, distribution or reproduction is permitted which does not comply with these terms. 